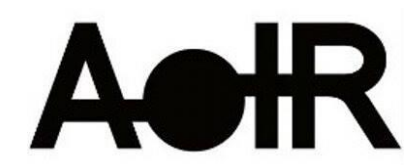

Selected Papers of \#AoIR2021:

The 22nd Annual Conference of the

Association of Internet Researchers

Virtual Event / 13-16 Oct 2021

\title{
NOSTALGIA AND THE BACKLOG: /R/PATIENTGAMERS AND THE TRANSACTIONAL NATURE OF LEISURE
}

\author{
Rainforest Scully-Blaker \\ University of California, Irvine
}

\section{Extended Abstract}

On November 11, 2011 Bethesda Game Studios released a long-anticipated installment in their acclaimed video game series, The Elder Scrolls V: Skyrim. For many, it was a day to retreat from one's earthly responsibilities and embark on a virtual adventure. For others, however, this was not the case. On the same day as Skyrim's release, Reddit user jetmax25 made a post to /r/gaming entitled "Being Poor Sucks" to lament the fact that they could not afford the brand-new game and were instead playing an older Bethesda title (2011). In the resulting comment thread, one supportive user remarked that there should be a community for people who wait to buy a game due to financial or other constraints. This comment spawned a chain of others that supported the idea and within thirty minutes, /r/patientgamers was created, a discussion board which serves as a stark reminder that while patience can be a virtue, it can also be a necessity.

As a piece of a larger project on slowness and slow play in game culture, this paper uses the findings of an investigation into the /r/patientgamers subreddit to account for the ways that our leisure time and our play have been assimilated by the logics of neoliberal, late capitalism. I do this by tracing classed experiences of slowness as they are experienced by video game players. The figure of the patientgamer was selected not just because of their explicitly protracted approach to video game consumption, but because the grows out of a frustration with the financial and temporal costs to access leisure. Through Foucauldian discourse analysis (Given 2008), two major themes were detected across a number of posts which traced how many players tried, and often failed, to slow down their lives in restful ways through their play and the conversations that emerged from the impulse to treat their leisure time as work. Specifically, users' nostalgia for their childhoods and their anxieties around possessing a video game backlog are both emblematic of the way that video game play has been made legible to capitalist logics such that any distinction between labour and leisure becomes moot. But can the work of play may be reframed to undercut logics of efficiency and productivity?

Suggested Citation (APA): Scully-Blaker, R. (2021, October). NOSTALGIA AND THE BACKLOG: /R/PATIENTGAMERS AND THE TRANSACTIONAL NATURE OF LEISURE. Paper presented at AolR 2021: The 22nd Annual Conference of the Association of Internet Researchers. Virtual Event: AolR. Retrieved from http://spir.aoir.org. 
/R/patientgamer's clear resistance to marketing hype and their intrinsic critique of the tech sector mantra that what is newest is best both come across as anticapitalist, yet much of how patientgamers speak of video gaming frames play as a transaction, as an investment of both money and time made in exchange for comfort. This comfort was emblematized in multiple discussion threads about so-called cozy games - "those games where, whenever you fire them up and begin a new adventure, there's that warm, embracing feeling that says, 'Welcome Home."' (WickedWenchOfTheWest, 2018). This pervasive notion of coziness forces us to reconsider the patientgamer's expression of nostalgic longing, what Boym (2001) calls the desire for "the repetition of the unrepeatable" (p. xvii). Given that video games generally allow one to play through the same stories as many times as they wish, the medium would seem to push against this sense of nostalgia, however a closer look at communal discussions revealed that patientgamers longed not for a return to the comfort of a familiar game world, but rather for a return to their childhood which was explicitly mourned as a time before the burden of temporal and financial obligations, a time before being aware of their own capitalist subjectivities.

Through the lens of theories on time, labour, and grievance (Ahmed 2018; Sharma 2014), I argue that the desire for comfort is a form of political stasis, an expression of dissatisfaction with the status quo which conserves hegemony by ignoring the difficult but necessary work of acting against an unjust system to bring about change (Keeling 2019). For example, the "backlog" originally referred to surplus resources held in reserve, it has come to refer to the exact opposite - an excess of tasks which perennially works complete. Within game culture it refers to a stockpile of titles that one has purchased but not played, but the ties to labour are unmistakable. Given the particularly transactional nature with which the /r/patientgamers framed video game play, those who no longer had the time to play as often as in their childhood were now faced with imposing backlogs which left them lamenting "hours worth of content to slog through" (EatenByWeirdFishes, 2019). This anxiety productively thwarts the received wisdom that play is a voluntary form of leisure and instead shows many feel held ransom by an obligation to relax (Agamben, 2011; Trammell, 2021). Ultimately, these forces of nostalgia and backlog are read as an indictment against late capitalism and against neo-liberal logics of independence and self-care through Deleuze's articulation of the control society in which "you never finish anything" (1990, p. 179).

This case study of /r/patientgamers holds relevance not just for the study of games and/as culture, but of how technocapitalism instrumentalizes all leisure and the consequences felt by those who try to slow their rhythms of consumption but do so without proper attention to issues of class and power. As Sharma notes, "slowing down does not necessarily change (and certainly does not ameliorate) the ways in which individuals are tangled together in time" $(2014$, p. 111). The transactional nature of play within patientgamer discourse shows how media products are routinely framed as supposed escapes but consumers nonetheless faithfully tether them to the same draining logics of labour, time, and value that many wish to forget when they turn to these virtual worlds for a reprieve. To conclude, this paper opens the door to asking whether slowness can be made uncomfortable in ways that subvert the ideal of productivity rather than reifying it. 


\section{References}

Agamben, G. (2011). Hunger of an Ox. In G. Agamben, Nudities (pp. 104-112). Stanford: Stanford University Press.

Ahmed, S. (2018). Refusal, Resignation and Complaint. feministkilljoys. Retrieved from: https://feministkilljoys.com/2018/06/28/refusal-resignation-and-complaint/

Boym, S. (2001). The Future of Nostalgia. New York: Basic Books.

Deleuze, G. (1992). Postscript on Control Societies. In G. Deleuze and M. Joughin (Trans.) Negotiations 1972-1990 (pp. 177-182). New York: Columbia University Press.

[EatenByWeirdFishes]. (2019, July 17). My thoughts after finally clearing my backlog: This was a huge fucking mistake. [Online forum post]. Reddit. https://www.reddit.com/r/patientgamers/comments/cebopw/my_thoughts_after_finally_cl earing_my_backlog/

Given, L. (2008). The Sage encyclopedia of qualitative research methods. Los Angeles, Calif: Sage Publications.

[jetmax25]. (2011, November 11). Being Poor Sucks [Online forum post]. Reddit. https://www.reddit.com/r/gaming/comments/m8rqh/being_poor_sucks/

Johnson, M. and Luo, Y. (2017). Gaming-value and culture-value: Understanding how players account for video game purchases. Convergence, 25.5-6.

Keeling, K. (2019). Queer times, black futures. New York: New York University Press

Sharma, S. (2014). In the Meantime: Temporality and Cultural Politics. Durham: Duke University Press.

Trammell, A. (2021). Torture, Play, and the Black Experience. GAME, 8.9.

[WickedWenchOfTheWest]. (2018, November 8). Cosy games? [Online forum post]. Reddit. https://www.reddit.com/r/patientgamers/comments/9vh4k4/cosy_games/ 